\title{
DAS 2015
}

\section{Fatigue resistance of low alloy steel after shot peening}

\author{
Denisa Závodskáa, ${ }^{\mathrm{a},}$, Mario Guagliano ${ }^{\mathrm{b}}$, Otakar Bokůvka ${ }^{\mathrm{a}}$, Libor Trško, ${ }^{\mathrm{a}, \mathrm{c}}$ \\ ${ }^{a}$ University of Žilina, Faculty of Mechanical Engineering, Department of Materials Engineering, Univerzitná 8215/1, 010 26 Žilina, \\ Slovak Republic \\ ${ }^{b}$ Politecnico di Milano, Department of Mechanics, Via La Masa 1, 20156 Milan, Italy \\ ${ }^{c}$ Research Centre of the University of Žilina, Univerzitná 8215/1, 01026 Žilina, Slovak Republic
}

\begin{abstract}
It is well known that shot peening is able to increase the fatigue strength and endurance of metal parts, especially with a steep stress gradient due to a notch. This positive effect is mainly put into relation with the ability of this treatment to induce a compressive residual stress state in the surface layer of material and to cause surface work hardening [1]. In this paper shot peening is applied on the $40 \mathrm{NiCrMo} 7$ low alloy steel and subsequently the surface was re-peened with glass beads to decrease the final surface roughness. Roughness, hardness and residual stress analysis were used for characterizing the strongly deformed surface layer. Low frequency fatigue tests were carried out to evaluate the effect of the applied treatment on fatigue life in the high cycle region. Results show fatigue strength increase in the high cycle region after the shot peening surface treatment.
\end{abstract}

(C) 2016 Elsevier Ltd. All rights reserved.

Selection and Peer-review under responsibility of the Committee Members of 32nd DANUBIA ADRIA SYMPOSIUM on

Advanced in Experimental Mechanics (DAS 2015)

Keywords: 40NiCrMo7 low alloy steel; fatigue lifetime; shot peening

\section{Introduction}

The fatigue damage reasons of structural materials have been investigated for more than 170 years; Wohler's curve incl. fatigue limit (referred to $\mathrm{N}=2 \times 10^{6} \div 10^{7}$ cycles) is known since 1858 . The stress vs. number of cycles plot (S-N dependence) incl. fatigue limit are the main parameters used for evaluation of fatigue properties of structural

\footnotetext{
* Corresponding author. Tel.: +421 415132632
}

E-mail address: denisa.zavodska@fstroj.uniza.sk 
materials $[2,3]$ However the fatigue damage of structural components is still the dominant one in the field of threshold state of materials.

Deformation strengthening of the surface layer is one of the methods used to increase the fatigue properties of structural materials. Surface strengthening can be performed by various methods as for example ultrasonic surface attrition, shot peening, deep rolling and so on. However for deformation strengthening of industrial structural components with general shape and dimensions is mostly used shot peening. Shot peening is a coldworking process, where the surface is bombarded with small and hard spherical media called shots $[4,5]$. Impact of every shot causes a plastic deformation of the surface and a dimple is created. Tension deformation which is necessary for creation of a dimple causes compressive residual stresses in the subsurface layers of the treated material. These compressive residual stresses mainly increase the time necessary for fatigue cracks initiation what in the final case significantly increases the total fatigue lifetime of a component or a construction [6,7].

In this paper the authors publish own results of experimental examination of low alloy steel's fatigue properties after shot peening application including relaxation of residual stresses during rotating bending fatigue loading.

\section{Experimental material and surface treatment}

As experimental material was used $40 \mathrm{NiCrMo} 7$ low alloy steel with chemical composition given in Table 1 and mechanical properties obtained in standard tensile test are presented in Table 2. The experimental material was in a state after heat treatment which consisted of quenching from $850{ }^{\circ} \mathrm{C}$ to mineral oil and tempering at $600{ }^{\circ} \mathrm{C}$ for $1 \mathrm{~h}$, cooling in air. The final microstructure after the heat treatment consist of high tempered martensite and residual austenite as is shown in the Fig. 1.

Table 1. Chemical composition of 40NiCrMo7 low alloy steel in wt. \%

\begin{tabular}{ccccccccc}
\hline $\mathrm{C}$ & $\mathrm{Si}$ & $\mathrm{Mn}$ & $\mathrm{S}$ & $\mathrm{P}$ & $\mathrm{Ni}$ & $\mathrm{Cr}$ & $\mathrm{Mo}$ & $\mathrm{Cu}$ \\
\hline 0.389 & 0.29 & 0.68 & 0.003 & 0.009 & 1.81 & 0.84 & 0.23 & 0.09 \\
\hline
\end{tabular}

Table 2. Mechanical properties of 40NiCrMo7 low alloy steel

\begin{tabular}{cccc}
\hline Yield point $[\mathrm{MPa}]$ & UTS $[\mathrm{MPa}]$ & Ductility $[\%]$ & Hardness HV10 \\
\hline 1170 & 1292 & 14.8 & 180 \\
\hline
\end{tabular}

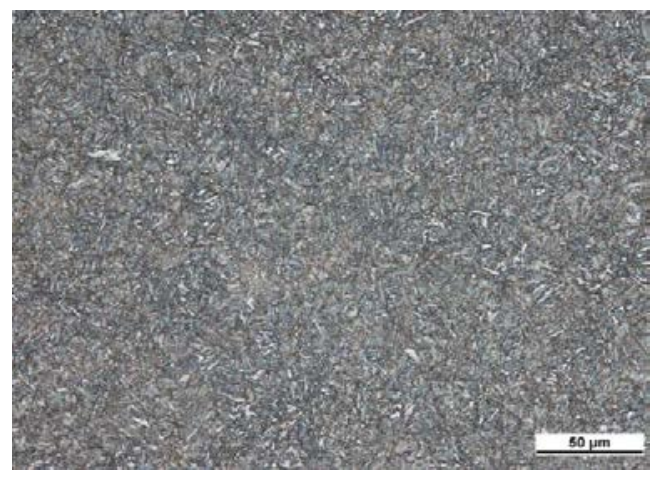

(a)

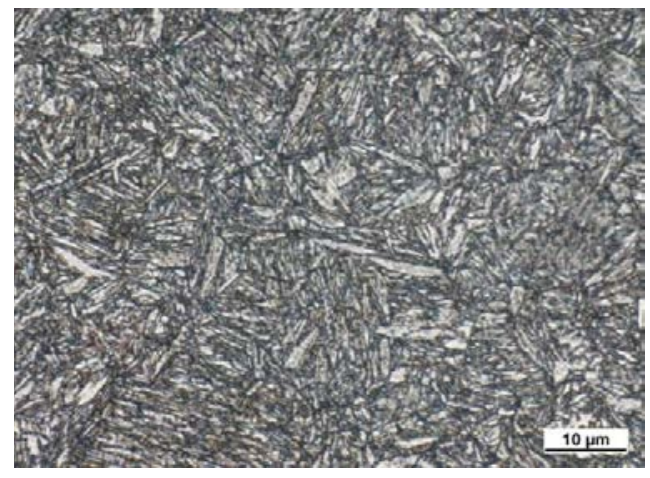

(b)

Fig. 1. Microstructure of 40NiCrMo7 low alloy steel (a) and in detail (b); cross section, etch. $3 \%$ Nital

Two sets of shot peened specimens - smooth specimen (11 PCS) (Figure 2a) and notched specimens (12 PCS) (Figure 2b) with geometry according to ISO 1143 [8], were tested with the aim to determine the fatigue limit $\sigma_{\mathrm{c}}$ at $\mathrm{N}=3 \times 10^{6}$ cycles. The shot peening treatment of specimens was realized with use of parameters: cast steel 
ball media (S170) with diameter of $0.43 \mathrm{~mm}$, Almen intensity 12A, coverage $100 \%$ and consequently the surface was shot peened with glass beads to decrease the final roughness.

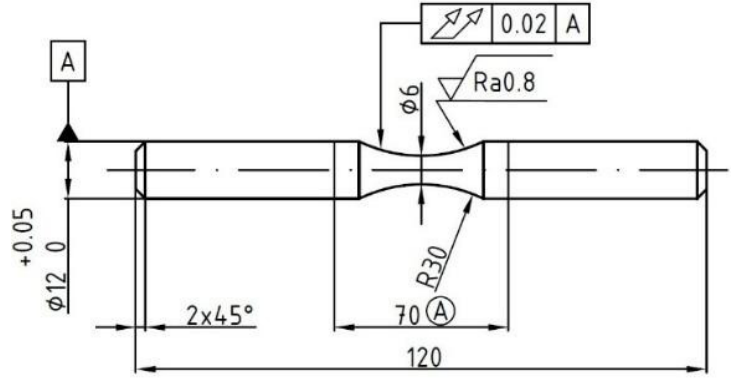

(a)

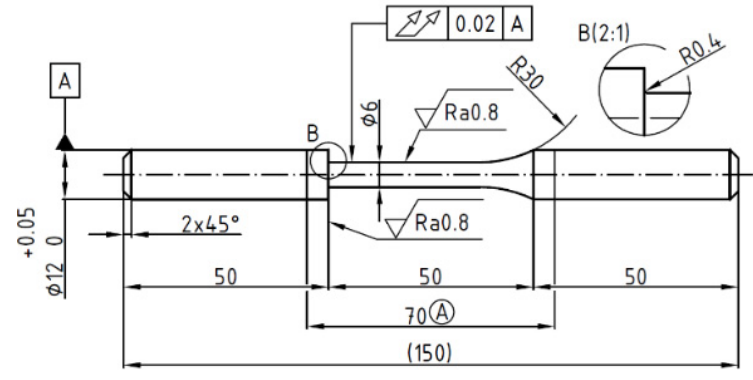

(b)

Fig. 2. The shape and the dimensions of smooth (a) and notched (b) specimens

\section{Residual stress measurement}

To obtain quantitative values of the residual stresses in the material X-ray diffraction (XRD) measurements were carried out with use of X-Stress 3000 Stress Tech device (Cr radiation $\mathrm{K} \alpha$, irradiated area $1 \mathrm{~mm}^{2}, \sin ^{2} \psi$ method, diffraction angles (20) scanned at different $\psi$ angles ranging from $-45^{\circ}$ to $45^{\circ}$ ). During the residual stress measurement the FWHM parameter (Full Width at Half Maximum) was also obtained, which is defined as the width of the diffraction peak in half of its height. It can be considered as a comparative index of the surface work hardening.

Residual stress profiles of shot peened smooth specimens were measured in the middle of the specimen, where the nominal diameter is $6 \mathrm{~mm}$ and the residual stress of shot peened notched specimen were measured on the $\varnothing 6 \mathrm{~mm}$ diameter along the notch. The residual stresses were measured on the fatigue specimens also after the end of a runout test.

From the measured values of the residual stress was constructed diagram which is provided in Fig. $3 a-$ the dependence of residual stress on the depth from the original surface. Based on measured results is evident that the shot peening process has been successful in accumulation of high values of compressive residual stresses in the surface layers of the material. When residual stress measurement was performed on a run - out test specimen it was observed, that significant part of the residual stresses has relaxed during the fatigue loading. The relaxation of the residual stresses is mainly connected with micro-plastic deformation process during the fatigue loading.

In the Fig. 3b is shown dependence of FWHM (Full Width at Half Maximum) vs. depth while FWHM gradually decreases in depth under the surface. It is sensitive to various microstructure properties as crystallite size (coherently diffracting areas), not-oriented micro-stress and mainly the dislocation density. A part of the FWHM signal is also related to the instrument in use, however, results obtained on one instrument are comparable [9]. In this particular case the FWHM can be understood as the index of work hardening. The decrease of the parameter correspond to decrease of the residual stresses and confirms that under $0.2 \mathrm{~mm}$ under the original surface the shot peening process had no effect. 


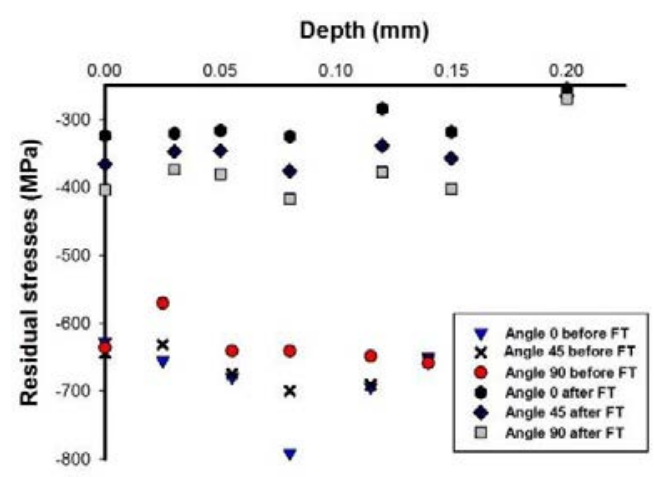

a)

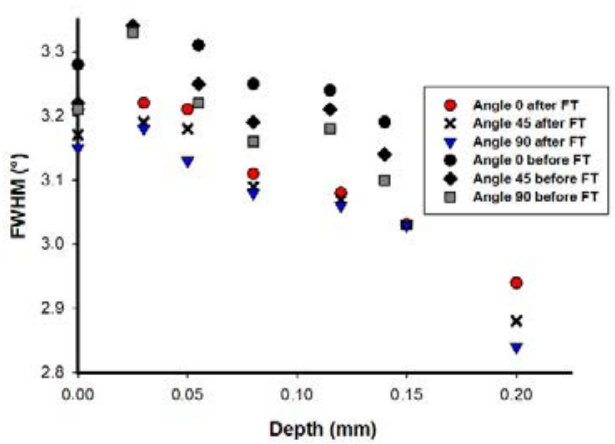

b)

Fig. 3. Distribution of residual stresses, low alloy steel, shot peened specimens, before and after fatigue tests (FT) (a) and distribution of FWHM shot peened specimens, before and after fatigue test (FT) (b)

\section{Fatigue tests}

Rotating bending fatigue tests (frequency $\mathrm{f}=30 \mathrm{~Hz}$, temperature $\mathrm{T}=20 \pm 5{ }^{\circ} \mathrm{C}$ and stress asymmetry ratio $\mathrm{R}=-1$ ) in high cycle region were carried out with use of experimental testing device Italsigma of the Department of Mechanics, Politecnico di Milano, Italy. For determination of the fatigue limit was used so called staircase method. Fatigue tests for shot peened smooth specimens (Fig. 4a) were carried out in the range of stress amplitudes from $\sigma_{\mathrm{c}}=720 \mathrm{MPa}$ to $\sigma_{\mathrm{c}}=640 \mathrm{MPa}$. The fatigue limit was determined for run-out number of cycles of $N_{c}=3 \times 10^{6}$ as a value $\sigma_{\mathrm{c}}=640 \mathrm{MPa}$ on a level with $5 \%$ failure probability. Fatigue tests for shot peened notched specimens (Fig. 4b) were carried out in the range of stress amplitudes from $\sigma_{\mathrm{c}}=540 \mathrm{MPa}$ to $\sigma_{\mathrm{c}}=460 \mathrm{MPa}$ and the value of fatigue limit was set for $N_{c}=3 \times 10^{6}$ cycles as $\sigma_{\mathrm{c}}=460 \mathrm{MPa}$ on a level with $5 \%$ failure probability.

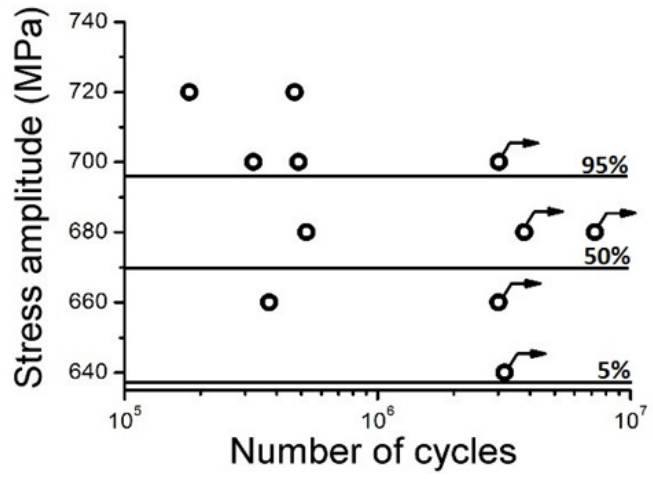

a)

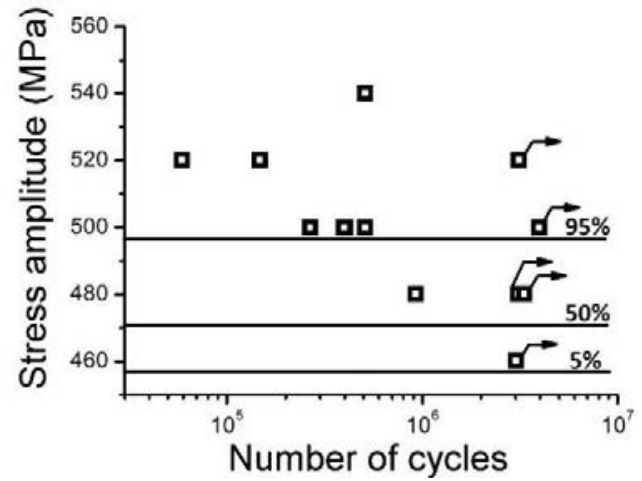

b)

Fig. 4. S-N diagram of 40NiCrMo7 low alloy steel for shot peened smooth specimen (a) and shot peened notched specimen (b)

\section{Discussion}

Increasing surface roughness after shot peening process is the main negative effect of this treatment. In most cases, increasing surface roughness causes decrease of fatigue strength of material. However, in case of surface strengthening, when the treatment parameters are balanced, the positive effect of the deformed surface layers overcomes the negative effect of the increasing roughness. Even in this case high surface roughness can avoid using of this treatment in many cases when it would cause other negative aspects like increased wear as for example in 
gears. For the purpose of decreasing of the final surface roughness after primary shot peening process was performed secondary peening with use of glass beads which removes the sharp edges of the dimples created during the primary peening process.

Fatigue test results of the smooth specimens (Fig. 4) can be compared with results published in [10] (Fig. 5a) where identical steel was tested in not peened state and after identical primary shot peening parameters (Almen intensity $12 \mathrm{~A}$, coverage $100 \%$ ), without the secondary glass beats treatment. Roughness of the not peened smooth specimens was $\mathrm{Rz}=5.84 \mu \mathrm{m}$ and their fatigue limit was $\sigma_{\mathrm{c}}=580 \mathrm{MPa}$ (Fig. 5a) [11]. After performing primary shot peening treatment with $12 \mathrm{~A}$ intensity and coverage of $100 \%$, the surface roughness significantly increased and it reached value of $\mathrm{Rz}=12.07 \mu \mathrm{m}$. Despite the high surface roughness the fatigue limit after the primary peening increased and it reached value of $\sigma_{\mathrm{c}}=690 \mathrm{MPa}$ (Fig. 5a). Secondary peening with glass beads resulted in finer surface roughness with value of $\mathrm{Rz}=0.51 \mu \mathrm{m}$. Even when still deep layer of compressive residual stresses was present (approx. $0.2 \mathrm{~mm}$ ) after primary and secondary treatment, peening with glass beads decreased the fatigue limit to value of $\sigma_{\mathrm{c}}=640 \mathrm{MPa}$ (Fig. 5a). Even when the fatigue limit after secondary peening is lower than of specimens treated only with shot peening, combined treatment still provides increase of fatigue limit for a value of $\Delta \sigma_{\mathrm{c}}=60 \mathrm{MPa}$ what represents $10 \%$ increase.

The probable reason of the fatigue life decrease after the glass beads peening can be found by comparison of the residual stress profiles (Fig. 5b). Secondary glass beats peening has changed the residual stress distribution is the sub-surface material layers. After primary peening with $12 \mathrm{~A}$ intensity and coverage of $100 \%$ the compressive residual stresses reached maximal value of $-800 \mathrm{MPa}$ and the strengthening effect was lost in depth of approx. 0.12 $\mathrm{mm}$ under the original surface. After secondary peening the maximal value of compressive residual stresses reached only about $-700 \mathrm{MPa}$, however the residual stress field is shifted deeper and reaches value of $0.2 \mathrm{~mm}$ under the original surface. It seems that the fatigue life improvement effect is more about the maximal value of compressive residual stresses than about the depth of the residual stress field. Even when the roughness was considered and specimens with better roughness had lower fatigue limit, also other factors as for example surface integrity need to be considered to verify this statement.

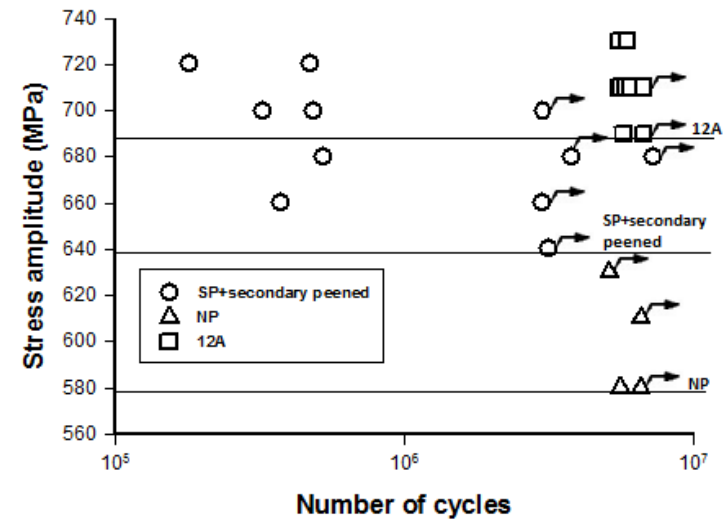

(a)

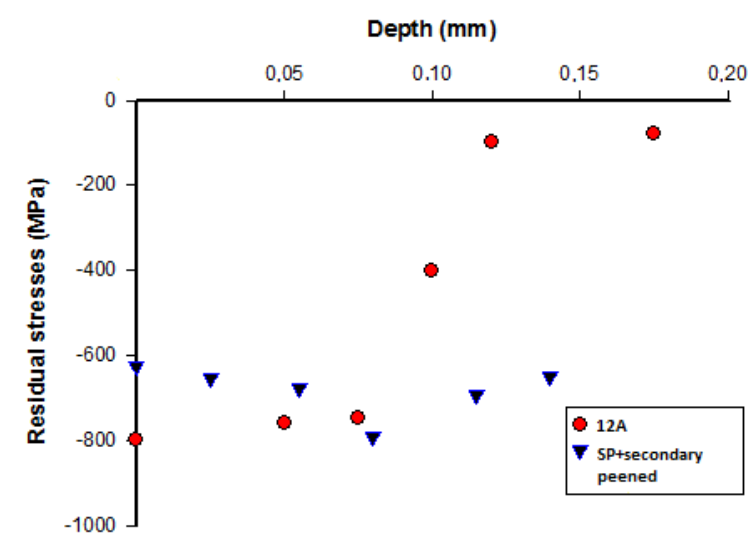

(b)

Fig. 5 S-N diagram of 40NiCrMo7 low alloy steel in not peened, shot peened and shot peened + secondary peened specimens (a) and residual stress profile of shot peened and shot peened + secondary peened specimens (b) 


\section{Conclusions}

According to experimental works carried out on $40 \mathrm{NiCrMo} 7$ low alloy steel can be concluded:

- Shot peening performed with Almen intensity 12A and coverage of $100 \%$ and consequent secondary peening with glass beads was able to improve the fatigue limit up-to $10 \%\left(\Delta \sigma_{c}=60 \mathrm{MPa}\right)$ for smooth specimens.

- Secondary peening with glass beads was able to reduce the surface roughness by removing sharp edges of dimples created during the primary shot peening process from $\mathrm{Rz}=12.07 \mu \mathrm{m}$ to $\mathrm{Rz}=0.51 \mu \mathrm{m}$ what represents a significantly finer surface character.

- Despite decreased surface roughness, the secondary peening with glass beads decreased the fatigue limit when compared to only shot peened specimens for $\Delta \sigma_{\mathrm{c}}=50 \mathrm{MPa}$.

- Decrease of the fatigue limit due to secondary glass beads peening is probably connected with redistribution of the residual stresses when the maximal value of compressive stresses changes from $-800 \mathrm{MPa}$ to $-700 \mathrm{MPa}$, however the strengthened depth increases from $0.12 \mathrm{~mm}$ to $0.2 \mathrm{~mm}$ under the original surface.

\section{Acknowledgements}

The research was supported by the Slovak Research and Development Agency under the contract No. SK-CZ-2013-0047 (20\%), Scientific Grand Agency of MESS of SK and Slovak Agency of Science, grant No. 1/0123/15 (10\%) and by the ERDF and Slovak state budget for the project Research Centre of University of Žilina, ITMS $26220220183(70 \%)$.

\section{References}

[1] K. Miková, et al., Int. J. Fatigue. 55 (2013) 33-42.

[2] O. Bokủvka, et al., Fatigue of Materials at Low and High Frequency Loading. Žilina - EDIS, 2014.

[3] P. Skočovský, et al., Náuka o materiáli. Žilina - EDIS, 2014.

[4] A. A. S. Torres, H. J. C. Voorwald, Int. J. Fatique. 24 (2002) $877-886$.

[5] R. B. Heaton, 1989. Shot Peening. Metal Finishing, 1989.

[6] L. Trško, et al., Materials and Design. 57 (2014) $103-113$

[7] F. Abadie, et al., Shot Peening: A Dynamic Application and its Future, second ed., Wetzikon, Metal Finishing News, 2009.

[8] ISO 1143: 1975 Metals - Rotating Bar Bending Fatigue Testing.

[9] L. Trško, et al., Metallic Materials. 53 (2015) 239-243.

[10]S. Bagherifard, et al., $12^{\text {th }}$ Int. Conf. on Shot Peening, Goslar, Germany, (2014) $25-32$.

[11]S. Bagherifard, et al., Key Eng. Mater. 488 - 489 (2012) 290 - 293. 